\title{
Medical Oncologist
}

National Cancer Institute

\section{Source}

National Cancer Institute. Medical Oncologist. NCI Thesaurus. Code C17838.

A doctor who specializes in treating cancer. Some oncologists specialize in a particular type of cancer treatment. For example, a radiation oncologist specializes in treating cancer with radiation. 